\title{
COVID - 19 on Lockdown, Social Distancing and Flattening the Curve - A Review
}

\author{
Adela Paingan Balasa
}

\begin{abstract}
The novel corona outbreak that started in Wuhan China in Autumn 2019, has infected and killed hundreds of thousands of people all over the world. People around the world are scared because a vaccine has not yet been developed to cure this disease. Scientists and health experts around the world are working hard to develop medical countermeasures to control the spread of the COVID 19 outbreak. COVID-19 pandemic created an unprecedented world crisis to our health and changed the way we perceived our world and our everyday lives. To be able to contain the pattern of transmission of this deadly virus, health experts suggests to each one of us to observe the required safety measures such as social distancing and washing our hands with soap and water in a regular basis and observe a proper hygiene. The role of different mass media channels skyrocketing in our lives on different levels. During this time of the pandemic, mass media have been highly recognized as strongest forces in promoting solidarity to people around the world. It has been followed by an increasing volume of research closed to the footsteps of technological transformations intended to map mass media strongest impacts on how we perceived ourselves during this time of the pandemic. Why lockdown and social distancing amid corona virus? When will this outbreak end? What does flattening the curve mean in relation to Corona Virus? This paper discusses the significance of social distancing, lockdown and flattening the curve as countermeasures in order to win the fight against COVID 19. Meanwhile, other interventions and prevention measures such as, lockdown, community quarantine and social distancing are all the necessary interventions and prevention measures that governments all over the world are urging their citizens to do in order to delay and prevent the spread as well as to flatten the curve against COVID-19.
\end{abstract}

Keywords-COVID 19, Pandemic, Flattening Curve, Lockdown - Quarantine, Social Distancing.

\section{INTRODUCTION}

In order to have a clear understanding of why government and health experts are imposing the law of house lockdown, quarantine and social distancing, the concept of EPIDIMOLOGY will be discussed. Coronavirus disease (COVID-19) is an infectious disease caused by a newly discovered coronavirus (WHO, 2020). A virus is an infecting agent that has no potential to multiply if it has not entered into a living cell.

Further discussion of this article will tackle the transmission dynamics of COVID 19. There are many speculations that COVID 19 originated from bats. Many people believe that bats are the carriers of the coronavirus. In this case of COVID 19s, there is another speculation that this virus has been transmitted to the tangerine leopard gecko.
There are some people who believe that the scales of the tangerine leopard gecko can cure most types of diseases and because of this belief, it is very easy to transmit the virus from tangerine to human. There is already strong evidence on the strong transmission of the virus from human to human. The spread of the disease is a way of direct contact between the infected and the susceptible person. It is also possible to be infected by COVID 19 through contaminated objects, such as stainless steel.

According to the National Institute of Health (2020), in their article titled: "The new coronavirus stays for hours on surfaces" reports that the virus that causes coronavirus disease 2019 (COVID-19) remains from several hours to days in aerosols and on surfaces. Scientists from the National Institute of Health, CDC, UCLA and Princeton University further added in their report that Severe Acute Respiratory Syndrome Coronavirus 2 (SARS-CoV-2) was detectable in aerosols for up to three hours, up to four hours on copper, up to 24 hours on cardboard and up to 72 hours on plastic and stainless steel.

If a traveler infected with Coronavirus travels to a country and transmits the disease, it is called an imported case and if one case is connected to one positive case, it is called a local transmission case. If one case has no travel history and has no contact to a carrier patient, it is called a community transmission. A community transmission is possible in COVID - 19, due to the stability of the virus throughout the environment and due to the existence of asymptomatic carriers. An asymptomatic carrier is a person who has contracted a virus but is not manifesting any of the symptoms it causes (Quaglia, 2020). Examples of this are coughing or having a slight fever. However, they have the potential to transmit these symptoms to others. This is due to their lack of awareness that they are already carriers of the COVID - 19 and these carriers of the virus are continuing to mingle with people in their offices, meetings, restaurants, hotels and malls to name a few. They don't also care if people will be socialized with them since they know that they don't have any travel histories to infected countries. Due to these profiles of COVID - 19, there are possibilities of community transmission. This is the scenario of how COVID - 19 patients get infected.

It is now apparent to each of us that we must all play our part and must obey our governments' strong rules on community quarantine in the fight against the global pandemic of Covid 19. By staying at home, the exposure of infection from symptomatic to asymptomatic carriers is 
limited.

\section{LITERATURE REVIEW}

BBC (2020) reported that in the Singapore version of the International Business Times website that North Korea's first confirmed Corona virus (COVID 19) patient had been shot dead" and further stated that the country's leader Kim Jongun "sanctioned the execution of the first North Korean patient tested positive for the deadly strain of the virus". The North Koreans believe that "culling" or killing potential animal carriers (such as bats) of COVID 19 or any other types of diseases, is the first way to stop this outbreak, and other outbreaks such as African swine fever or bird flu. From the North Korean stance, it is the only remedy to stop the outbreak (Hassanin, 2020). However, based on human rights and ethical standards, culling is a huge violation if this is the way used to fight COVID 19.

The second way to stop COVID 19 is strengthening the potential of everyone to fight against this disease. This way is through educating people to observe proper hygiene (washing hands with soap), developing a vaccine to cure COVID 19 and to take care of each other's health. Until now, a vaccine has not yet been developed to cure COVID 19 has still not yet been developed. Scientists and medical experts have started to develop the vaccine and are experimenting in many field trials to address challenges such as safety issues (Hassanin, 2020).

Dynavax (2020) in their report emphasized that the Coalition for Epidemic Preparedness (CEPI) has initiated 8 partnerships to improve understanding and to develop vaccines against the novel coronavirus. The report added that programmes will leverage the rapid response of platforms that have been already been supported by the Coalition for Epidemic Preparedness (CEPI) as well as their new partnerships. According to the report of Dynavax (2020), the aim of the programmes is to advance COVID-19 vaccine candidates into clinical testing as quickly as possible.

The third viable way to fight against COVID 19 is the strategy of social distancing. According to Torres (2020) in her article, titled: "What to know about social distancing strategies amid coronavirus outbreak", she emphasized that social distancing prevents the COVID 19 pandemic to spread and it should be to maintain an approximate distance of 6 feet or two meters from others. Furthermore, her report states that the World Health Organization (WHO) is urging the public to leave at least 3 feet, or 1 meter, between them self and anyone who is coughing or sneezing.

There are many people asking why there is a need to put all people into quarantine, or house lockdown? Is it not possible that only the sick people (COVID 19 carriers) have been isolated? How about the people on a daily wage? How will they be able to earn a living to survive every day? Clarifications and clear understanding with these peoples' inquiries will be tackled the main discussions of this article.

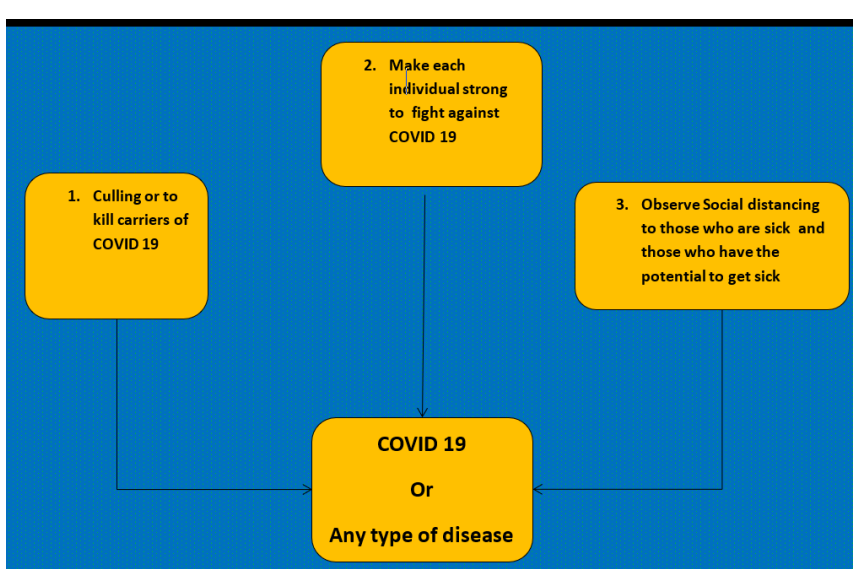

Fig. 1. Three Ways Used to Stop the Outbreak of COVID-19 Or Any Type of Disease

Source: (created by the author)

There are three main discussions in this article as shown on Figure 1. These are the three ways designed to stop the outbreak of COVID 19. The first way is culling or killing the carriers of the virus which is a violation against human rights and ethical standards by the United Nations. The second way is to make each individual strong to fight against COVID-19 and the third way is social distancing as an important way of intervention to flatten the curve of COVID 19.

\section{Reproductive Number of COVID - 19}

According to Zhang, et. al (2020) in their discussion on their study titled: "Estimation of the reproductive number of novel coronavirus (COVID-19) and the probable outbreak size on the Diamond Princess cruise ship: a data-driven analysis", the use of existing data and the epidemic model that incorporates those data can provide the estimated $\mathrm{RO}$ of COVID - 19 during the early stage experienced on the Diamond Princes cruise ship. Based on their estimated RO, it was about 2.28 to 3.58 (Zhang et al., 2020).

A reproductive number ( $\mathrm{RO})$ is the total number of transmissions of a sick person by which the person is infected by COVID-19. If the reproductive Number is $>1$, the potential transmission of COVID-19 is fast. To have a clear understanding about the reproductive number ( $\mathrm{RO})$, let's say that Miguel is a carrier of COVID-19 then there is the possibility to transmit the disease to at least two more people. So, in this case, the reproductive number (RO) is 2.5, meaning $>1$ and therefore it is a fast transmission.

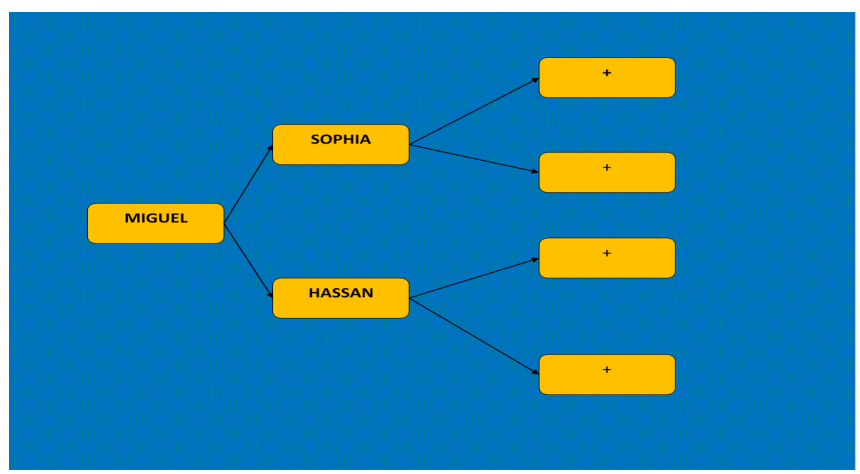

Figure 2: The Reproductive Number of COVID-19 Fast Transmission Source: (created by the author) 
Figure 2 illustrates how Miguel transmitted COVID-19 to two individuals such as Sophia and Hassan. In this stage from the diagram, there are already greater than ( $>$ ) COVID-19 because of Miguel. These are the individuals such as Sophia and Hassan and four more patients. These new coronavirus carriers will still have the potential to transmit more new carriers of COVID-19 until it continues to multiply even if there is no imposition of separating between the sick and the healthy ones.

Zhang, S. et al. (2020), calculated that the MaximumLikelihood (ML) value of R0 was 2.28 for COVID-19 outbreak at the early stage on the ship. The result of their calculation stated that the median with 95\% confidence interval (CI) of R0 values was 2.28 (2.06-2.52) estimated by the bootstrap resampling method. Furthermore, the report stated that the probable number using of new cases during the next ten days would gradually increase, and they estimated that cumulative cases would reach 1514 (1384-1656) at the tenth day in the future. Finally, they stated in their report that if the R0 value was reduced by $25 \%$ and $50 \%$, the estimated total number of cumulative cases would be reduced to 1,081 (981-1177) and 758 (697-817), respectively.

This is the objective of having the measure of community quarantine to decrease the reproductive number (RO) of carriers from COVID-19. The community quarantine will lessen the probability of spreading COVID-19 and this will happen if it is observed and implemented effectively.

\section{Other Intervention to Fight Against COVID-19 -} Flattening the Curve

According to Meredith (2020) in his article titled: "Flattening the coronavirus curve: What this means and why it matters", he defined that in epidemiology, the curve refers to the projected number of new cases over a period. He added in his explanations that the steep rise of the curve depicted the rise of the coronavirus infections. Meredith (2020) added to his report that the idea of flattening the curve is to stagger the number of new cases over a longer period, so that people have better access to care.

Figure 3 illustrates the importance of interventions. The peak of the curve shows that without measures of intervention, the potential of COVID 19 transmission is uncontrollable, and in this case, front liners would not be able to cope. No interventions show the fast increase of cases as most people are becoming sick at the same time. In the case with intervention, the increase will slow down, and cases will minimize. It is necessary to flatten the curve to delay the peak and slow down the numbers of infected patients.

Most scientists and health experts continuously work hard 24 hours round the clock in order to innovate and create vaccines for COVID 19. Until now, there are still no available vaccines for COVID 19, and there are many challenges being faced by many countries all over the world due to the limitations of testing kits with even the World Health Organization stressing the need for citizens to take collective action.

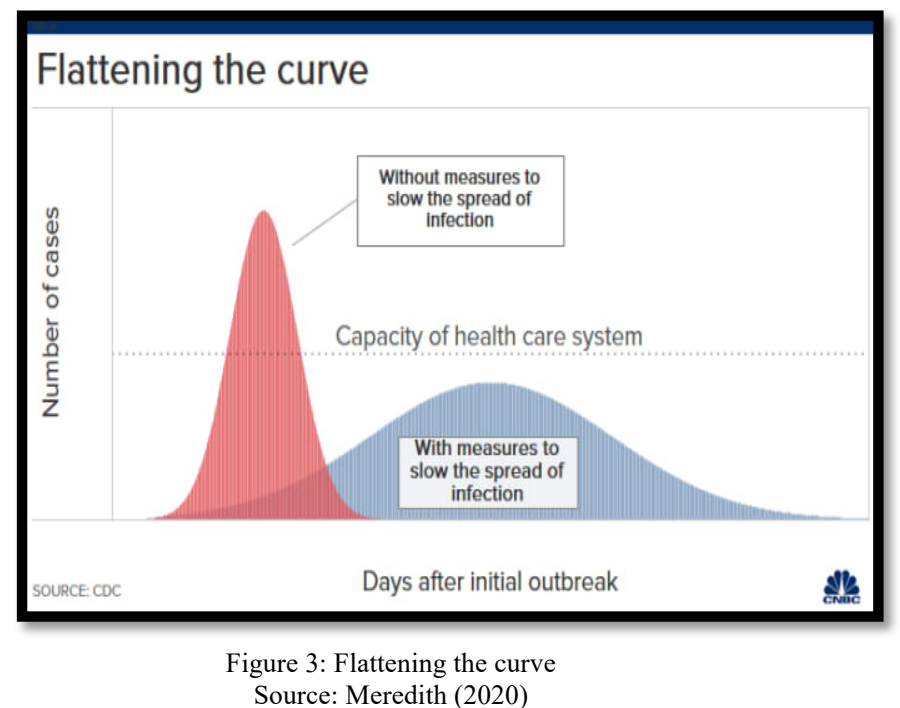

As responsible citizens of the world during this time as the global crisis caused by the coronavirus pandemic is surging, all of us must contribute to help these scientists and health frontlines all over the world by washing our hands regularly, avoiding touching eyes, nose and mouth, maintaining social distancing, practicing respiratory hygiene and seeking medical care if someone has a fever, cough or any difficulty breathing. All these measures, if people on this planet will listen and cooperate, can be beneficial to our health front liners in flattening the curve of COVID- 19.

The downside scenarios that brought about by COVID-19 on investors is its implications to disrupt the global supply chains and economic spillovers from the real economy to global financial markets. World's largest oil producers are facing challenges on their decisions on how to maintain their current levels of production despite of the continuous reduction of energy prices. Economic slowdowns resulted to a huge reduction of energy demand due to CVID-19. According to the report of Segal and Gerstel (2020) they emphasized that members of the Organization of the Petroleum Exporting Countries (OPEC) and a few other major oil producers met to discuss an additional cut of 1.5 million barrels per day through the end of June in response to the outbreak. Due to the increasing uncertainty of business activities all over the world, financial market volatility still expected to happen until the time when the virus is contained.

\section{CONCLUSION}

To conclude, Covid-19 is a virus that started in the province of Wuhan China that spreads all over world. It affects the economic standard, political system and even religious activity globally. Covid-19 brings a lot of damage in the lives of every human beings in all parts of the earth. It was declared by the World health Organization as a global pandemic on March 11, 2020, Cucinotta, D. and Vanelli, M. (2020). It is called a mysterious virus because until now scientists and drug makers cannot yet find a medicine for this dreadful disease. Culling or killing the carriers of the virus, make each individual strong to fight against COVID-19 (Hassanin, 2020) and social distancing (Torres, 2020) are the three main interventions used to stop the high risk of transmission of COVID-19 pandemic. In addition of these 
three main interventions discussed in this paper, public health officials of all nations in the world recommends important everyday preventive actions that include staying home when sick; covering mouth and nose with flexed elbow or tissue when coughing or sneezing. Dispose of used tissue immediately; washing hands often with soap and water; and cleaning frequently touched surfaces and objects (UNICEF, 2020). It is therefore a responsibility to each one of us to take action to prevent the further spread of COVID-19 reducing its impacts and support all the preventive measures.

\section{ACKNOWLEDGMENT}

The author would like to thank Dr. Noorul Shaiful Fitri Abdul Rahman, Department of Logistics Management HoD of International Maritime College Oman for helping and encouraging me to write this article as well as my Irish friend Miss Emma Mclister who edited the language of this manuscript.

\section{REFERENCES}

Bandoy, D. (2020). COVID - 19 case forecast and reproductive number. [Online]. [Viewed 29 March 2020]. Available from https://twitter.com/darwinbandoy/status/1239441487680528385

BBC Monitoring Insights (2020). Analysis: Unverifiable North Korea coronavirus execution claim spreads. [Online]. [Viewed 29 March 2020]. Available from: https://monitoring.bbc.co.uk/product/c201hte3

Dynavax, (2020). Dynavax and CEPI Announce Collaboration to Support Global Effort to Develop a Vaccine for Coronavirus (COVID-19). [Online]. [Viewed 29 March 2020]. Available from: https://www.efe.com/efe/usa/comunicados/dynavax-and-cepiannounce-collaboration-to-support-global-effort-develop-a-vaccinefor-coronavirus-covid-19/50000209-4205397

Hassanin, A. (2020). Coronavirus origins: genome analysis suggests two viruses may have combined. [Online]. [Viewed 29 March 2020]. Available from: https://www.weforum.org/agenda/2020/03/coronavirus-originsgenome-analysis-covid19-data-science-bats-pangolins/

Hodgson, J. (2020). The pandemic pipeline. Springer Nature Limited. doi: $10.1038 / \mathrm{d} 41587-020-00005-\mathrm{z}$.

Meredith, (2020). Flattening the coronavirus curve: What this means and why it matters. [Online]. [Viewed 29 March 2020]. Available from: https://www.cnbc.com/2020/03/19/coronavirus-what-doesflattening-the-curve-mean-and-why-it-matters.html

National Institute of health (2020). New coronavirus stable for hours on surfaces. [Online]. [Viewed 29 March 2020]. Available from: https://www.nih.gov/news-events/news-releases/new-coronavirusstable-hours-surfaces

Quaglia. S. (2020). CORONAVIRUS: HOW ASYMPTOMATIC CARRIERS SPREAD A DISEASE LIKE COVID-19. [Online] [Viewed 29 March 2020]. Available from: https://www.inverse.com/mind-body/coronavirus-howasymptomatic-carriers-spread-virus-like-covid-19

Torres, E. (2020). What to know about social distancing strategies amid coronavirus outbreak? [Online]. [Viewed 29 March 2020]. Available from: https://abcnews.go.com/Health/social-distancing-strategiesamid-coronavirus-outbreak/story? id $=69648478$

WHO (2020). Coronavirus. [Online]. [Viewed 29 March 2020]. Available from:https://www.who.int/health-topics/coronavirus\#tab=tab_1

Zhang, s. et. al (2020). DOI: https://doi.org/10.1016/j.ijid.2020.02.033 Estimation of the reproductive number of novel coronavirus (COVID19) and the probable outbreak size on the Diamond Princess cruise ship: A data-driven analysis. International journal of infectious diseases.

Zhang, S. et al. (2020). Estimation of the reproductive number of novel coronavirus (COVID-19) and the probable outbreak size on the
Diamond Princess cruise ship: data-driven analysis. Int J Infect Dis. 93:201-204.

Segal, S. and Gerstel, G. (2020). The Global Economic Impacts of COVID19. [Online]. [Viewed 24-4-2020]. Available from: https://www.csis.org/analysis/global-economic-impacts-covid-19

Cucinotta, D. and Vanelli, M. (2020). WHO Declares COVID-19 a Pandemic. [Online]. [Viewed 24-4-2020]. Available from: https://www.ncbi.nlm.nih.gov/pubmed/32191675.

UNICEF (2020). Key Messages and Actions for COVID-19 Prevention and Control in Schools. Online]. [Viewed 24-4-2020]. Available from: https://www.who.int/docs/default-source/coronaviruse/keymessages-and-actions-for-covid-19-prevention-and-control-inschools-march-2020.pdf?sfvrsn=baf81d52_4

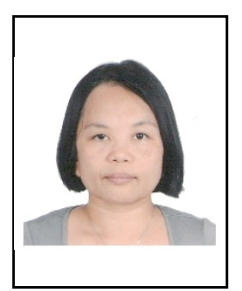

Adela Paingan Balasa. Bai, Lagayan, Abra, Philippines. February 08, 1963. Doctor of Public Administration, The University of Manila, Manila, Philippines, October 2002.

She is presently working as an ASSOCIATE PROFESSOR of Economics at Intranational Maritime College Oman, Sohar, Sultanate of Oman, from February 2009 up to the present. 